\title{
The Role of Resilience in the Relationship between Stress and Depression among Medical Students
}

\author{
Rosnel Tan, Mary Rachelle Reyes-Wapano, $\mathrm{PhD}$ \\ Xavier University - Ateneo de Cagayan
}

\begin{abstract}
Young adults especially are vulnerable to depression during university years, with those taking up highly demanding courses like medicine showing high prevalence. Protective factors have been identified to moderate the negative effects of stress on a person. One such factor is resilience, which this study examined and its role in the relationship between stress and depression among medical students. The total population of medicine students enrolled during the data gathering was 510. Using Cochran's formula, a five percent $(5 \%)$ margin of error and a confidence level of ninety five percent $(95 \%)$, the sample population taken was 220 . A hierarchical linear regression was performed first to examine the relationship between stress and depression, stress and resilience and depression and resilience. Stress and depression were found to be positively correlated while both stress and depression were found to be negatively correlated with resilience. Moderation analysis was then used to determine the extent of resilience's effect on the relationship between stress and depression. Results showed that resilience moderated the relationship between stress and depression among medical students.
\end{abstract}

Key words: stress, depression, resilience

\section{INTRODUCTION}

$\mathrm{M}$ ental health problems continue to rise in all parts of the world, with an estimated 230 million people suffering from different kinds of mental illnesses such as depression, epilepsy, Alzheimer's disease and schizophrenia (Al Qahtani A \& Al Qahtani N, 2017; Chelala, 2013; Jai Prakash \& Prabhu, 2014). Among the mental health problems mentioned in these studies, depression makes up more than 50 percent of the said estimate which is roughly around 120 million people (Al Qahtani A \& Al Qahtani N, 2017; Chelala, 2013; Jai Prakash \& Prabhu, 2014). Currently, it ranks as the fourth leading cause of mental health problems worldwide and is projected to rank second after ischemic heart disease by the year 2020 (Al Qahtani A \& Al Qahtani N, 2017; Chelala, 2013; Jai Prakash \& Prabhu, 2014).

The World Health Organization, which conducts annual studies on mental health, has reported that depression has become the leading cause of ill health and disability worldwide, which saw an increase of more than 18 percent between the years 2005 up to 2015. The said report also established that there are more than 300 million people who are now living with depression (WHO, 2018). Parekh (2017), in his APA review also reported that depression affects an estimated 1 in 15 adults or 6.7 percent in any given year and 1 in 6 people or 16.6 percent will experience depression at some time in their life which means it can strike any person at any time (Parekh, 2017).

Among the countries in Southeast Asia, the Philippines has the highest incidence of depression as reported in a study by Abadiano, Corvera, Yao, Susvilla, Albior, Salapi, Sombrio, Maceda, Pepito, Ronolo, Kho, Bargamento, Paninsoro, Malapitan, Solon and Salahid (2015). In a 2015 study conducted by the World Health Organization on the Global Burden of Disease, it was reported that 3.3 million Filipinos suffer from depressive disorders, with suicide rates in 2.5 males and 1.7 females per 100,000 (WHO, 2018).

Young adults are especially vulnerable to depression as reported by WHO (2018) in their latest report on depression that it is the second leading cause of death among people aged between 15 to 29 years old. Another study has reiterated the vulnerability of this particular age group but by defining those individuals aged 18 - 26 years or also called emerging adults (Corathers, Kichler, Fino, Lang, Lawrence, Raymond, Yi-Frazier, Dabelea, Liese, Saydah, Seid, \& Dolan, 2017 as cited by Anasuri \& Anthony, 2017) as individuals who are in a period of developmental stage wherein a variety of problems with regard to education, emotions, and financial opportunities are encountered. This is a time when it can be difficult for these individuals to overcome such problems or stressors without enough knowledge and preparation on handling, adapting, and overcoming adversity that comes with transitioning into young adults (Anasuri \& Anthony, 2017). Individuals belonging in this age group specifically those attending university were found to be at risk to depression according to Eisenberg, Gollust, Golberstein and Hefner (2007) as cited by Kapıkıran and Acun-Kapıkıran (2016). Ibrahim, Kelly, Adams and Glazebrook (2013) have also indicated in their study that depressive symptoms are prevalent among college students (cited by Talwar, 2016). This prevalence of depression is indicated also in a systematic review and meta-analytic study of university students by Sarokhani, Delpisheh, Veisani, Sarokhani, Manesh and Sayehmiri (2013). Wang (2013) also noted that existing literature has indicated a well-established relationship between depression and suicide ideation among college students with depression as a major predictor.

Although there are many contributing factors of depression, stress is considered to be one of the most frequent causes for people who suffer from it according to Essel and Owusu (2017). The study compared stress to a physical force 
which when encountered and not handled well by a person, would result to extreme pressure and lead to an adverse effect like suicide (Essel \& Owusu, 2017). Ku (2017) also gives support to the effects of stress on a person by highlighting this relationship. This study explored precursors to depression and stress has been considered as an important factor in its development. Ku's study revealed that stress activates cognitive susceptibility factors that can also contribute to the development of depression (Ku, 2017). Mohamad, Mohamad, Subhi, Baidi and Nor Asshidin (2016), also reported that mental health problems do not develop on its own but can be caused by certain factors in the environment such as family or financial problems, which work to pressure a person

Buchanan (2012) has reported that the transition from adolescence to adulthood is considered a critical period of a person's life due to the many changes that comes with it. This is a time that is usually stressful for students, especially those who attend universities or higher education system (Buchanan, 2012 as cited by Abdel Wahed \& Khamis Hassan, 2015). This was also noted by Parekh (2017) in his review, that on average, the onset of depression is usually during the late teens to mid-20s (Parekh, 2017).

These depressive symptoms are even more pronounced with those university students who have highly demanding courses like medicine (Prakash \& Prabhu, 2014). This study highlighted the immense stress that medical students face due to a heavier workload which is extremely demanding compared to other courses (Prakash \& Prabhu, 2014). Medical students face pressure from academic, social and financial aspects, which are three common sources of stress for them (Prakash \& Prabhu, 2014).

Puthran, Zhang, Tam and Ho (2016) also reported that medical schools are known to be stressful environments for students, which leads to higher prevalence of depression among medical students as compared to students from other courses (Puthran, Zhang, Tam \& Ho, 2016). Factors like difficulty in adjusting to the new and demanding environment, long hours of study, heavy workload and financial stress were identified as stressors that resulted to depressive symptoms. These factors were reiterated in a study by TabalipaI, Fuganti de SouzaI, PfützenreuterI, LimaI, TraebertI and TraebertI (2015) who reported that medical students are at high risk of developing depression and anxiety disorders, which can reach levels of severity that are more than enough to bring important consequences to emotional, mental and physical well-being.

Puthran et al (2016) conducted an evaluation of the global prevalence of depression among medical students, which included epidemiological studies wherein the frequency of a disease like depression, are estimated, psychological factors such as low self-esteem that can cause depressive symptoms, educational factors such as heavy workload and social factors such as family problems and relationship with parents. The study was done in order to identify groups that may require interventions to which the result showed a global prevalence of depression among medical students, with onethird affected by it (Puthran et al, 2016).

This global prevalence of depression can also be seen in studies conducted in medical schools in Asian countries like Vietnam (Pham, Bui, Nguyen, Nguyen, Tran \& Vu, 2019), Nepal (Basnet, Jaiswal, Adhikari \& Shyangwa, 2012) and China (Mao, Zhang, Liu, Zhu, He \& Wang, 2019), where there was also a reported high prevalence of depression among the medical students with factors such as heavy study workload, demanding environment and financial difficulties cited to be some that caused depressive symptoms to develop.

In the Philippines, a search for local literature yielded only a few studies about stress and depression but not among medical students. There was a study conducted in a medical school in Baguio but it examined the health-related quality of life among its medical students (Domantay, 2014). Another local study on medical students focused on academic stress (Garan-Giller, Dator, Juan, Querubin, Sevilla \& Calimag, 2019), while another one was about academic resilience but on a broad range of health science students (Salvacion, Sana \& Yanilla, 2018). A recent study on resilience among Filipinos saw it measured in terms of a collective whole or national resilience amidst the current pandemic (Callueng, Aruta, Antazo \& Briones - Diato, 2020). This study can hopefully fill in the gap in this area by examining the role of resilience in the relationship between stress and depression among the medical students in a local university.

Factors from the environment affect individuals differently, which can also trigger different adaptive responses to stress according to Tafet and Nemeroff (2016). This difference depends on psychological and biological aspects of the interaction between the stressors and the resources of an individual (Tafet \& Nemeroff, 2016). There are some studies that has identified resources or protective factors which can help an individual cope with stress and lessen its impact on the person, thus lessening symptoms of depression, one of which is resilience (Daniel, 2011; Janus, Lehrer, Gloria \& Steinhardt, 2017; Doll, 2013; Gettinger \& Stoiber, 2009 as cited by Yates, Tyrell and Masten (2014).

Janus et al (2017) in their study of depression among adolescent girls, has found that resilience has a moderating effect on the relationship between stress and depressive symptoms. They found that the relationship of increased perceived stress on depressive symptoms was weakened for those students who reported higher resilience. The moderating role of resilience was also shown in a study of college students by Solomon (2013) wherein results showed that higher resilience is positively correlated with academic achievement and was negatively correlated with perceived stress, while those with lower resilience showed higher levels of perceived stress and poor academic performance (Solomon, 2013). Sagone and De Caroli's (2013) study of adolescents also showed that those who experienced high levels of resilience reported that they are more able to handle changes 
and challenges in different aspects of their lives especially in the academic area (Sagone \& De Caroli, 2013).

This study examined the role of resilience on the relationship between stress and depression among medical students in a university in the city of Cagayan de Oro. In particular, it sought to answer the following:

1. What are the levels of depression, stress and resilience among medical students?

2. What is the relationship between stress and depression among medical students?

3. What is the relationship between depression and resilience among medical students?

4. What is the relationship between stress and resilience among medical students?

5. To what extent does resilience moderate the relationship between stress and depression?

\section{CONCEPTUALIZATION}

This study examined the role of resilience on the relationship between stress and depression among medical students. Lazarus and Folkman (1984) defined stress as an experience that happens when a person perceives that the demands exceed the personal and social resources the individual is able to mobilize (Lazarus, 1977; Lazarus \& Folkman, 1984). This theory further stated that the stress and emotions that an individual experiences depend on how that individual evaluates the events happening around the person. If the person perceives that the event that is significant is beyond the person's control, high levels of stress is experienced.

In some people, the level of stress experienced is due to repetitive negative thoughts about the event that is significant to the person (Ehring \& Watkins, 2008). This particular mental process is shared across a wide range of psychological disorders, such as substance use disorders, anxiety disorders, depression, eating disorders, pain disorders, and sleep disorders (Harvey et al., 2004) as cited by Devynck, Rousseau and Romo (2019). Rood, Roelofs, Bo“gels and Meesters (2010), would call this mental process as a negative cognitive style which is the tendency to make negative attributions and inferences about the causes, consequences, and implications of stressful events in one's life, a concept that was proposed by Aaron Beck with his Negative Cognitive Triad theory in 1987.

Several researchers are also in agreement that stress and negative emotions are closely associated with each other, and that depression according to some studies, is a form of stress response (Kiecolt-Glaser, McGuire, Robles \& Glaser, 2002; Sternberg, Chrousos, Wilder\& Gold, 1992, as cited by Du, Huang, An \& Xu, 2018).

Depression, according to Dr. Aaron Beck (1987), is caused by negative thoughts, generated by dysfunctional beliefs, which typically are the primary cause of depressive symptoms. He stated that there are three main dysfunctional belief themes that govern depressed people's thinking. The first is, the person believes that he or she is defective or inadequate; second, the person believes that all of his or her experiences result in defeats or failures, and third is when the person believes that the future is hopeless. Beck (1987) called these three themes as the Negative Cognitive Triad. When these beliefs are present in someone's cognition, depression is very likely to occur, if it has not occurred already. A direct relationship occurs between the amount and severity of someone's negative thoughts and the severity of their depressive symptoms. These negative cognitions, will then in turn, further maintain and exacerbate negative affect, leading to a vicious cognitive-affective circle with enhanced depressive symptoms (Teasdale, 1988; Watkins, 2008). In other words, the more negative thoughts a person experiences, the more depressed that person will become (Corey, 2009).

Resilience is a core concept defined by Wagnild (2009) as a personal strength that describes individuals who are courageous and adaptable despite adversities encountered (Wagnild \& Young, 1990). Wagnild and Young (1993) identified two components of resilience which are personal competence and acceptance of self and life. Personal competence consists of self-reliance, independence, determination, mastery, resourcefulness and perseverance. Acceptance of self and life consists of adaptability, flexibility and a balanced life perspective (Wagnild \& Young, 1993).

\section{LITERATURE REVIEW}

Literature and studies on the prevalence of stress and depression among college students, specifically on medical students are presented below with studies on how resilience can be a protective factor.

\section{Stress among medical students.}

Stress is especially magnified for those students with highly demanding courses like medicine, wherein its high prevalence is one of the most important concerns that is welldocumented worldwide (Almojali ,Almalki , Alothman, Masuadi \& Alaqeel, 2017; Rosiek et al, 2015; Prakash \&Prabhu, 2014; Shah, Hasan, Malik \& Sreeramareddy, 2010). This is also reiterated by Melaku, Mossie and Negash (2015) in the study they conducted, wherein they reported that globally, medical students have been found to be at risk of psychological stress, mental disorders, and decreased life satisfaction (Melaku, Mossie \& Negash, 2015).

This prevalence of stress among medical students has been reported in many studies from countries such as in Pakistan who reported a $60 \%$ prevalence rate, Thailand at $61 \%$, Malaysia at $42 \%$, the United States at $57 \%$ and Saudi Arabia at 63\% (Waqas, Khan, Sharif, Khalid \& Ali, 2015; Sreeramareddy, Shankar, Binu, Mukhopadhyay, Ray \& Menezes, 2007; Saipanish, 2003; Abdel Rahman, Al Hashim, Al Hiji\& Al-Abbad, 2013 as all cited by Almojali , Almalki , Alothman, Masuadi\&Alaqeel in 2017). A study conducted at 
a public sector medical college in Mumbai showed incidence of stress in 73.5\% medical students (Prakash \& Prabhu, 2014).

When Eva, Islam, Mosaddek, Rahman, Rozario, Iftekhar, Ahmed, Jahan, Abubakar, Wan Dali, Razzaque, Bin Habib and Haque (2015) conducted a cross-sectional study of eight medical schools in Bangladesh, they found that out of the 990 medical students who participated, more than half or $53 \%$ of them were stressed out, resulting to having both psychological and physical disorders (Eva et al, 2015).

These findings are consistent with those studies done by Anuradha, Dutta, Raja, Sivaprakasam and Patil (2017) when their study revealed that perceived stress is higher among medical students in the higher age group and those in their final year and another done in Tehran University of Medical Sciences by Borjalilu, Mohammadi and Mojtahedzadeh (2015), which saw a result of $83 \%$ of medical students reporting perceived stress.

Garg, Agarwal and Dalal (2017) described the high levels of stress among medical students as a trend that has transcended factors like the sociocultural aspect, economic status and curriculum of the medical course (Garg, Agarwal \&Dalal, 2017).

Yusoff, Abdul Rahim, Baba, Ismail, Mat Pa and Esa (2013), cited by Melaku et al (2015), have noted that the huge amount of new information that medical students have to learn at a very limited time, especially during pre-clinical meetings, often weigh them down. This then result to feelings of distress and frustrations, especially when they are not able to handle all the lessons they need to review and perform poorly during exams (Melaku et al, 2015).

O'Rourke, Hammond, O'Flynn and Boylan (2010) has reported that the amount of excessive stress encountered during medical school predisposes the students to have problem-solving difficulties, poor concentration and eventually develop mental health problems like depression (O’Rourke et al, 2010 as cited by Melaku et al, 2015).

In addition, stress among medical students can disrupt their mental state, compromise decision-making which can cause lower class attendance. All these factors can have adverse effects on the overall performance of the students (Melaku, Mossie\&Negash, 2015).

Bedewy and Gabriel (2015) demonstrated in their study that the most common sources of stress among medical students were related to both academic and psychosocial pressures. Heavy study load, maintaining the required standard grade, enormity of the academic curriculum, frequency of exams were among those academic factors reported in their study. While high parental expectations, sleeping difficulties and worries about the future are among the psychosocial pressures they face (Bedewy \& Gabriel, 2015). High parental expectations also figured in some studies such as those by Anuradha, Ruma Dutta, Raja, Sivaprakasam and Patil (2017) and that of Shah, Hasan, Malik and
Sreeramareddy (2010) as one of the sources of stress for medicine students.

Difficulty in time management, hectic schedule, increasing study load, long duration of the course, sleep problems and a very competitive environment are factors that cause stress which are reported by Merchant, Mulkawar and Nayak (2018) in their study of 1,300 undergraduate medical students from government and private medical schools in India.

Other sources of stress such as poor or low grades, difficulty in comprehending the lessons, failure to provide answers during recitations, lack of skills during medical practice and insufficient time for study was identified by Elias, Ping and Abdullah (2011) when they cited a study by Yusoff et al (2010).

Saeed, Bahnassy, Al-Hamdan, Almudhaibery and Alyahya (2016) have stated in their study that the training which medical students need to go through is for the purpose of preparing them to take care of the health of future patients. However, their training is so physically and mentally taxing that it can have adverse effects on their own overall mental health. Their study have shown the worrying levels of stress among medical students, to which they have proposed that there is a lot of work to be done in terms of providing ample support to reduce the prevalence of stress and promote good health both physically and psychologically (Saeed et al , 2016).

Stress is very common globally among medical students as was reported by several researchers from countries among them Pakistan, Thailand, Malaysia, the United States, Saudi Arabia, Bangladesh and India. Heavy study loads, maintaining the required standard grade, the extent of the academic curriculum, frequency of exams were among those academic factors that cause stress among medical students. In addition, psychosocial factors like high parental expectations, a competitive environment, time management and worries about the future cause medical students to feel high amounts of frustrations and distress resulting to sleep problems, absenteeism, poor concentration and low grades. Feelings of frustration and distress usually lead to mental health problems one of which the most common is depression.

Stress is a part of a student's life but it is prevalent especially for those who are taking up medicine as seen in the different studies mentioned. Given the evidence from literature, this study aims to examine the level of stress among medical students.

\section{Depression among medical students}

Depression is especially pronounced among medical students, a detail which have been widely studied with its prevalence among the medical community having been cited 
in different researches (Soliman, 2013; Ibrahim \& Abdelreheem, 2014; Wahed \& Hassan, 2016; Prakash \&Prabhu, 2014).

In a review of 15 peer-evaluated studies spanning years between 1980 up to 2016, Onyishi, Talukdar, Sanchez, Olaleye, Medavarapu, et al (2016) reported that there is a higher trend of prevalence of depression among medical students. It comprises increased levels of burnout and suicidal ideation making psychological distress quite common among medical students and professionals (Onyishiet al, 2016).

This is supported by a number of other systematic reviews that have been conducted globally for various studies that have reported anxiety and depression among medical students (Sarkar, Gupta \& Menon, 2017). Sobowale, Zhou, Fan, Liu, Sherer (2014) have also found that medical students have higher rates of depression as compared to the general population of students in a university in mainland China (Sobowale, Zhou, Fan, Liu \& Sherer, 2014).

Banerjee and Chatterjee (2016) have cited similar findings in their study, when they reviewed data from a 2009 cross sectional web-based survey which showed that, compared to the general population, medical students experience depression, burn out and mental illness at a higher rate, with mental health worsening over the period of medical training (Banerjee \& Chatterjee, 2016).

Sobowale (2016) have reported on a meta-analysis which spanned four decades of research, wherein there is 28 percent of medical students found to be depressed while 5.8 percent of them have considered suicide. There are also data analyzed from studies by some researchers from Singapore which examined around 63,000 medical students across the globe. In Europe, there is 20 percent reported depressed medical students, 31.8 percent in the Middle east while 30.3 percent from North America (Sobowale, 2016).

Data from other studies on medical students (Chang, Gitlin \& Patel, 2011; University of Manchester Centre for Mental Health and Risk, 2012) have noted that around onethird up to $90 \%$ of suicide is precipitated by mental illness and that depression accounts for about one half so those who have attempted to do so (cited by Miletic, Lukovic, Ratkovic, Aleksic \& Grgurevic, 2013).

A more recent meta-analysis done on cross-sectional and longitudinal studies published prior to September 2016 have yielded an overall prevalence of depression or depressive symptoms among medical students as $27.2 \%$ (Rotenstein, Ramos, Torre, Segal, Peluso, Guille, Sen \& Mata, 2016).

Yusoff et al (2013) have previously reported that healthy students develop depression and stress after starting their medical schooling. They also cited that intense competition for getting postgraduate training and job opportunities could be an added cause for psychological disorders.
Prakash and Prabhu (2014) have stated that medicine is extremely demanding in addition to having a heavier workload compared to other courses because a large curriculum is covered in just a short period. Coupled with other major sources of stress such as academic, social and financial factors, depression becomes prevalent among medical students as a result.

The results of the study of Prakash and Prabhu (2014) have shown 64\% of prevalence rate of depression among medical students. This finding supports other studies that reported a prevalence rate of depression among medical students, ranging from $65.5 \%$ to $71.5 \%$ within the last decade.

Puthran, Zhang, Tam and Ho (2016) meanwhile, believe that medical schools are stressful environments which results to a higher prevalence rate of depression among medical students compared to those from other disciplines.

The higher prevalence of depression among medical students has been established as per the several studies in the previous paragraphs. Academic, social and financial factors are usually the major sources of stress for medical students. Other factors like heavier workload due to a large curriculum that should be covered in a short time, intense competition for training and job opportunities also add to the stressful environment that medicine students have to face. Hence the higher levels of burnout, suicidal ideation, anxiety and other forms of mental health problems, with depression being the most common, are experienced by the medical students during and after the program of study, as compared to the general population.

The prevalence of depression among medical students is established through numerous studies and it is usually caused by major sources of stress like academic, social and financial factors. Given the evidence from literature, this study examined the prevalence of depression among medical students.

Relationship between stress and depression among medical students

Numerous studies have reported that medical students are more exposed to several stressors, which makes them more prone to depression than other students from different courses (Al Raddadi, Aljabri, Kareem, Alattas and Alkhalawi, 2017; Cuttilan, Sayampanathan and Chun-Man Ho, 2016; Puthran, Zhang, Tam \& Ho, 2016). Symptoms of depression have been attributed to stress from personal stressors but more from the medical school environment (O’Reilly, McNeill, Mavor, et al, 2014 as cited by Houpy, Lee, Woodruff \& Pincavage, 2017).

Abdulghani, Al Kanhal, Mahmoud, Ponnamperuma and Alfaris (2011) as cited by Sohail (2012), have stated that high levels of stress may have a negative effect on cognitive functioning and learning of students in medical school (Sohail, 2012). When Dyrbye, Thomas, Massje, Power, Eacker, Harper et al (2008) cited by Sohail (2012), made a 
comparative study of stress experiences between medical students and students from other courses, literature review revealed that medical students are the ones who perceived higher stress. $\quad$ Dyrbye et al (2009) repeated their study on a different sample of students from Canada and the US, which showed consistency from their previous 2008 study which also showed high prevalence of depression, anxiety and psychological distress when compared to the general population (cited by Sohail, 2012).

These findings were further strengthened in a study by Mannapur, Dorle, Hiremath, Ghattargi, Ramadurg and Kulkarni (2010) when they described medical students as victims of the immense mental stress that medical education entails (cited by Basnet, Jaiswal, Adhikari \& Shyangwa, 2012).

Saravanan and Wilks (2014) have explored the various stressors that significantly predicted anxiety and depression with the results corresponding with previous studies done by Alvi, Assad, Ramzan and Khan (2010) who found high examination standards, numerous test activities, limited free time, difficult lessons and heavy workload as major stressors for the development of anxiety and depression among medical students (as cited by Saravanan \& Wilks, 2014).

Different stress levels were shown to be associated with mild to moderate degrees of depression among $97.2 \%$ of medical students in a tertiary medical school institute in Puducherry, India, when Kumar, Kattimani, Sarkar, and Kar (2017) conducted their study there. Their study found that of the 444 respondents, there were $83.7 \%$ who had moderate, high or very high stress levels the result of which is a prevalence rate of $84.8 \%$ of them having depression (Kumar, Kattimani, Sarkar \& Kar, 2017).

In terms of local literature, there is lack of evidence of studies made on stress and depression among medical students or studies on resilience which can be addressed by this present study.

Several studies have established how stressful medical schools are with medicine students experiencing different kinds of mental health problems. One of the most common health problems among medical students is depression that is attributed to the immense mental stress both from personal but more so from the medical school environment itself. Stressors such as high examination standards, numerous test activities, limited free time, difficult lessons and heavy workload are some of the major causes of high levels of stress that can result to negative effects on cognitive functioning and learning of medicine students. Hence, anxiety and depression have become common among medical students.

The relationship between stress and depression has been well-established by several studies, particularly among medical students. Given this evidence from literature, this study examined the relationship between stress and depression and its prevalence among medical students.

\section{RESILIENCE}

Resilience is a concept that has been defined and studied for several years now (Pinquart, 2008). Wagnild and Young (1993) defined resilience as a resource that can encourage psychological well-being and constructive growth, regardless of the different levels of stressors faced by a person. Cicchetti and Garmezy (1993) have defined it as a source of strength that helps a person overcome hardships, survive various stresses and rise above difficulties (cited by Pinquart, 2008).

A theory on resiliency was proposed through studies done by Fergus \& Zimmerman (2005) and Zimmerman and Brenner (2010). Their resiliency theory offers a context that focuses on a strengths-based method in understanding the development of children and adolescents, for the purpose of designing interventions (Zimmerman, 2013).

The factors that may interrupt the development of individuals and become at risk to mental stress, behavioral problems and health problems are the focus of the theory which promotes positive variables from a contextual, social and individual aspect. These positive variables or promotive factors (Fergus \& Zimmerman, 2005) function by helping a person resist or challenge adverse effects of various stressors (Zimmerman, 2013).

\section{Resilience as a protective factor against stress and depression}

The numerous studies on stress and depression has encouraged some researchers to study and cite some protective factors that can help alleviate the adverse effects of stress on a person and one of these is the study by McCann, Beddoe, McCormick, Kedge, Adamson and Huggard (2013) as cited by Eva et al, (2015) wherein they stated the importance of promoting and developing resilience in the workplace especially in health professions. This will ensure that stress is reduced and a positive and favorable environment will enhance productivity (Eva et al, 2015).

Some studies have shown that resilience and stress are associated, with resilience described by Wagnild and Young (1993) as a factor of personality that can moderate the negative effects of stress (cited by Solomon, 2013). Other studies like that of Petrie (2010) on adolescents with cystic fibrosis, found that they had lower perceived stress when their resilience levels are high (cited by Solomon, 2013).

Janus, Lehrer, Gloria and Steinhardt (2017) studied stress and depression among adolescent girls and found that resilience moderates this relationship. The results of their study showed a positive relationship between depressive symptoms and stress, while having a negative relationship with resilience. There was also a significant interaction of both stress and resilience on depressive symptoms, which means that the impact of stress on depression was weakened 
for those adolescent girls who had higher resilience (Janus, Lehrer, Gloria \& Steinhardt, 2017).

Houpy et al, (2017) have proposed that one way to lessen the negative effects of stressors is to develop resilience in preventing burnout and help students succeed after encountering difficult experiences. A study by Zhao, Guo, Suhonen et al (2016) of medical and nursing students in Finland have shown a relationship between higher levels of resilience and better subjective well-being (as cited by Houpy et al, 2017).

Lower levels of distress in medical and psychology students in Australia was also associated with high levels of resilience (Bacchi \& Licinio, 2016, as cited by Houpy et al, 2017), showed moderating effects on the negative life events that medical students in China went through (Peng, Zhang \& Li et al, 2012, cited by Houpy et al, 2017), and a higher quality of life scores and a more positive perception of the educational atmosphere among medical students in Brazil as reported by Tempski, Santos and Mayer et al (2015) as cited by Houpy et al (2017).

The present study explored the prevalence of depression among medical students in a local university in Cagayan de Oro City. It also explored how resilience can affect the relationship between stress and depression.

Based on the aforementioned literature, numerous studies have examined the prevalence of stress and depression among medical students. Factors such as academic, social and financial stress have been commonly mentioned as contributors to stress among the medical students with most of them experiencing depression as a result. A growing body of literature has also investigated protective factors such as resilience and its moderating role in the relationship between stress and depression to find out its moderating effects. Despite the number of studies on stress and depression, these are mostly conducted in western or other Asian countries.

A search on local literature yielded few studies which investigated stress and depression among medical students. There has also been few to no moderation studies done examining this particular relationship between stress and depression with resilience as a protective factor. This study aimed to fill in the gap through a moderation study of the role of resilience in the relationship between stress and depression among medical students in a local university in the city.

\section{Research Design}

Quantitative research using moderation analysis was performed for this study. Moderation analysis was used wherein the moderator variable, which in this study is resilience, is a variable that has the ability to affect the strength or the direction of a relationship between two existing variables. This study then examined the role of resilience and whether it can moderate the relationship between stress and depression among the medical students.

\section{Research Environment}

Considering that several studies have established the prevalence of stress and depression among medical students (Al Raddadi, Aljabri, Kareem, Alattas \& Alkhalawi, 2017; Cuttilan, Sayampanathan \& Chun-Man Ho, 2016; Puthran, Zhang, Tam \& Ho, 2016; O'Reilly, McNeill, Mavor, et al, 2014 as cited by Houpy, Lee, Woodruff \& Pincavage, 2017), this study was conducted at in a local University

\section{Respondents and Sampling Procedure}

The participants of this study were the Level 1 to Level 4 medical students enrolled in the local University. The Cochran's formula is used to calculate the sample size $\left(n_{o}\right)$ given the estimated proportion of the population (p), with the selected critical value of desired confidence level ( $\mathrm{z}$ ) and a margin of error (e) or the desired level of precision. It's a random sampling formula to estimate sampling size and is used when the population is infinite. Following the Cochran's formula, given the population of 510 and a five percent $(5 \%)$ margin of error with a confidence level of ninety five percent (95\%), the number of respondents was 220 .

\section{Instruments used}

There were three instruments used in this study, the PSS or Perceived Stress Scale by Cohen, Kamarck, and Mermelstein, BDI or Beck Depression Inventory by Beck, Ward, Mendelson, Mock, and Erbaugh (1961) and RS - 14 or Resilience Scale -14 by Wagnild and Young.

\section{Perceived Stress Scale}

The Perceived Stress Scale (PSS) is the most widely used psychological instrument for measuring the perception of stress (Cohen, 1994). It is a measure of the degree to which situations in one's life are appraised as stressful. The items were designed to draw on how uncertain, uncontrollable, and burdened the respondents find their lives. The scale also includes a number of direct questions about the experienced stress at their current levels Reliability analyses after the pilot test showed Cronbach $\alpha$ of 0.736 for all items, but this was after removing three of them. The adapted scale was used for the tests of the respondents. For each question, the respondents were asked about their feelings and thoughts during the past month. In each question, they were asked how often they thought or felt in a certain way. There are some questions which are similar, but there are small differences between them and should be treated as a separate question. The choices are never, almost never, sometimes, fairly often, or very often.

The scoring for each item is on a 5 point scale ranging from never or 0 to almost always or 4 . The scores were obtained by reversing responses $\quad(0=4,1=3,2=2,3$ $=1 \& 4=0$ ) to the four positively stated items which in this case are items 4, 5, 7 and 8 and then summing them across all scale items. A short 4 item scale can be made from questions 2, 4, 5 and 10 of the PSS 10 -item scale. The ratings were then 
added up with scores ranging from $0-13$ considered low stress, scores from $14-26$ considered moderate stress and scores from 27 - 40 considered high perceived stress.

\section{Beck Depression Inventory}

Many studies have reported that the BDI has excellent reliability and validity. In a study done in a university in Taiwan, the analyses of the BDI on the data of Taiwanese undergraduates yielded an overall internal consistency coefficient of 0.90 and an 8-week test-retest reliability of 0.81 . A study done by Prakash and Prabhu (2014) in India to assess the prevalence of depression among their medical students also used the BDI (Beck, Ward, Mendelson, Mock, \& Erbaugh, 1961). Another study done in a medical school in a university in the Philippines, specifically Baguio City, also used the BDI in assessing the levels of depression among the medical students (Domantay, 2014).

in order to test the reliability of the BDI as an instrument in evaluating depression, a pilot test was administered to college students similar in age and gender to the prospective target respondents of this study. Reliability analyses after pilot test was conducted $b$ yielded a Cronbach $\alpha$ of 0.859 for all the 21 items. The BDI is a 4-point Likert-type self-report scale. Each item is composed of 4 statements. They are scored from 0 to 3 to reflect the increase of depression level, with 0 being the lowest. Participants are required to rate the intensity on one of the four statements in each item that best describes their feeling during the past two weeks. The ratings are summed up to yield a total score ranging from 0 to 63. A higher score indicates a higher level of depression symptom severity for the participant.

Resilience Scale - 14

The RS-14 by Surzykiewicz, Konaszewski and Wagnild (2019). Was used in this study. Reported psychometric properties of the RS-14 have demonstrated sound psychometric properties and a reliability coefficient of Cronbach's alpha $=0.90$ and greater 0.96. (Wagnild, 2014) .

The pilot test done yielded a Cronbach $\alpha$ reliability of 0.827 . This scale was also used in the study done by Aiena, Baczwaski, Schulenberg and Buchanan in Measuring Resilience with the RS-14: A Tale of Two Samples, October 2013. The 14 items are rated from 1 or strongly disagree to 7 or strongly agree. The respondents are asked to select the number which best indicates their feelings about a statement. The numbers selected will be added and rated as follows: 8298 for Very High Resilience Tendencies; 64-81 is High Resilience Tendencies; 49-63 is Average; $31-48=$ Low Resilience Tendencies; 14-30 = Very Low Resilience Tendencies

\section{Data Analysis}

This study assumed that resilience will serve as a buffer or as a protective factor by lowering the impact of stress experienced by the medical students, thus lowering the levels of depression. This research argument can best be analyzed by using moderation analysis. Moderation analysis is a good procedure to use when investigating changes of relationship between two variables as the function of a third variable (Field, 2013). This analysis includes analyzing the direct effects of the predictor variable which in this study is stress, to the outcome variable or depression, as well as the combined or interaction effects of the two predictor variables or the moderating effect. The requirements for a moderation analysis includes: 1) the predictor and the outcome variable must be continuous, although the moderating variable can be either categorical or continuous. 2) The assumption of normality for each of the variables must be satisfied, thus checking the skewness and kurtosis statistics that has to be closed to zero to assume normality of the distribution. 3) There must not be multicollinearity or very strong correlations between the predictor and the moderator. 4) The predictor and moderator must be transformed by centering in which this statistical process is automatically transformed by moderation analysis through Process by Hayes (2012).

\section{ETHICAL CONSIDERATIONS}

\section{Informed consent}

Consent was sought from the research participants. Participants were informed about the nature of the research study and what their role in it was. They were given the option to voluntarily participate or not in the study. They were assured that they were free to withdraw from the study at any time or withdraw any information previously given to the researcher

\section{Confidentiality}

The participants were assured that all the data, records and results of this study will be kept strictly confidential. Research documents such as the completed questionnaires was kept securely in a box and stored in a file cabinet with a lock and key, to which the only one with access is the study researcher. As for all the electronic information, all these were coded and secured using a password protected file on the personal computer of the study researcher who had the sole access to it. The file was opened or accessed only on the personal computer of the researcher to maintain the confidentiality and protection of its contents.

\section{Anonymity}

This study strictly upheld and maintained complete anonymity of the participants and did not collect/require personal information such as names, birthdates, phone numbers and physical or email addresses. Numbers were assigned on the completed questionnaires for each of the participants who were only asked to provide age, sex and year level, all of which were not retained after the data collection. In case of publication of the study, the participants will be given the option whether they want to be informed about it or not, with the result remaining completely anonymous. 


\section{RESULTS}

Levels of stress, depression and resilience among the medical students?

The average PSS or stress score of all medical students from Levels 1 to 4, after correlation analysis was performed is at 22.54 which falls under the range of scores between 14 - 26 or at the moderate stress level, according to the Perceived Stress Scale (Cohen, Kamarck, \& Mermelstein, 1983) scoring interpretation. This comprised $73 \%$ of the total sample population. This result is consistent with several studies, one of which was by Prabhu and Prakash (2014) of a public sector medical college in Mumbai, wherein $73 \%$ of the total population of medical students reported incidence of stress. Cross-sectional studies conducted by Eva, Islam, Mosaddek, Rahman, Rozario, Iftekhar, Ahmed, Jahan, Abubakar, Wan Dali, Razzaque, Bin Habib and Haque (2015) in eight medical schools in Bangladesh, reported that of the 990 medical students who participated, more than half or $53 \%$ of them were stressed out, resulting to having both psychological and physical disorders (Eva et al, 2015). In another study done in Tehran University of Medical Sciences by Borjalilu, Mohammadi and Mojtahedzadeh (2015), results showed that $83 \%$ of medical students reported perceived stress.

The average BDI or depression score of all medical students from Levels 1 to 4 after performing correlation analysis is at 15.55 , which according to the Beck Depression Inventory (Beck, Ward, Mendelson, Mock, \& Erbaugh, 1961) scoring interpretation, falls in the mild mood disturbance level of depression. The frequency table shows that $62 \%$ of the students fall within normal and mild level of depression. This result is the same with the study of Iorga, Dondas and ZugunEloae (2018) in a medical university in Romania wherein the researchers examined the relationship between perceived stress and depression among its medical students. The result of that study has identified a mild level of depression among its medical students, that is similar to other results from researches conducted in other medical universities (Iorga, Dondas \& Zugun-Eloae, 2018).

In the present study, Level 3 students have the highest mean of the BDI score at 16.82, while Level 4 or 4 th year students have the lowest mean at 14.54. It is during the Level 3 phase that the medical students begin residency in hospitals and is considered as the adjustment period from performing and meeting academic requirements as students to practicing the medical profession by working in hospitals

The average RS or resilience score of all medical students from Levels 1 to 4, after correlation analysis was performed is at 70.59, which according to the Resilience Scale - 14 (Wagnild, 1993) scoring interpretation, the level of resilience among medical students falls between the scores of $64-82$ or at the high resilience tendencies level. It consists of $51.56 \%$ of the total sample population.
The descriptive results (Table 1) show that the medical students generally perceived that they experience moderate amounts of stress $(M=22.54, \mathrm{SD}=5.42)$, and that their reported experience of depressive symptoms for the past two weeks is also in the moderate level $(\mathrm{M}=15.55, \mathrm{SD}=$ 8.61). Moreover, the respondents tend to have high resilience tendencies $(\mathrm{M}=70.59, \mathrm{SD}=13.09)$.

The relationship between stress and depression among the medical students?

Stress and depression were found to be positively correlated, with $\mathrm{r}=0.623, \mathrm{n}=240, \mathrm{p}=0$. When the value of stress increased, depression also increased and vice versa which is the same as the result in a study by Kumar, Kattimani, Sarkar, and Kar (2017) of medical students in a tertiary medical school institute in Puducherry, India. The study showed that different stress levels were shown to be associated with mild to moderate degrees of depression among $97.2 \%$ of medical students. This study also found that of the 444 respondents, there were $83.7 \%$ who had moderate, high or very high stress levels the result of which is a prevalence rate of $84.8 \%$ of the medical students having depression (Kumar, Kattimani, Sarkar \& Kar, 2017). This was cited in studies by Al Raddadi, Aljabri, Kareem, Alattas and Alkhalawi, (2017), Cuttilan, Sayampanathan and Chun-Man Ho, (2016), Puthran, Zhang, Tam and Ho, (2016), wherein it was reported that medical students are more exposed to several stressors, which makes them more prone to depression than other students from different courses.

The relationship between depression and resilience among the medical students

Depression and resilience were found to be negatively correlated with $\mathrm{r}=-0.652, \mathrm{n}=239, \mathrm{p}=0$. This means that when the value of depression increased, resilience decreased and vice versa. This was consistent with the results of the study on the prevalence and relationship between depressive symptoms and resilience among African American women in a community - based primary health care center, wherein higher resilience showed a negative correlation with depressive symptoms (Holden, Bradford, Hall, and Belton (2013).

\section{The relationship between stress and resilience among medical students}

Stress and resilience were found to be negatively correlated, with $\mathrm{r}=-0.583, \mathrm{n}=239, \mathrm{p}=0$. When the value of stress increased, resilience decreased and vice versa. This result is the same as the findings in another study of pharmacy students whose resilience scores showed a negative or inverse relationship with depression and showed that the more resilient the students were, the less stress was experienced (Jones, 2020).

As for the associations between variables, all three variables are moderately correlated to each other, using the conventional interpretation for the degree correlation 
coefficient (Schober, Boer, and Schwarte, 2018). However, it can be observed that in terms of direction, the correlation between stress and depressive symptoms $(r=.627)$ is positive, implying a direct relationship between the two variables. The association between resilience to both stress $(\mathrm{r}=-.584)$ and depressive symptoms $(r=-.653)$ are negative, implying an inverse relationship.

\section{CONCLUSION}

The results showed that when it came to stress levels, most of the medical students' scores fell within the range of 14 - 26 which is considered to be in the moderate stress level according to the Perceived Stress Scale. Upon looking at the four levels of medical students though, it was noted that Levels 1 and 3 medical students However, in terms of levels of depression, most of the medical students' scores fell within the range of 11 to 16 or on the level of mild mood disturbance according to the scoring interpretation of the BDI. Although perceived stress among the medical students was moderate, most of them experienced mild mood disturbance only which can be explained by their scores in the Resilience Scale wherein most of them showed high resilience tendencies.

Moderation analysis showed that resilience moderated the relationship between stress and depression or that the presence of resilience had an impact on the relationship between stress and depression among the medical students.

\section{RECOMMENDATIONS}

Literature has established that medical schools are known to be highly stressful environments, which contribute to the prevalence of depression among medical students, some of whom resort to suicide. There were studies though which has highlighted protective factors like resilience that buffers or weakens the effect of stress on a person, thus lessening its impact on the person, thereby lessening symptoms of depression.

Future researchers can expand the scope of the study to other schools of medicine or to students taking up other highly demanding courses like Law and Nursing to further enhance some of its objectives, such as examining the prevalence of stress and depression. This will give the school administration insight on what programs to create that focuses on the mental health of the students. Future researchers can also expand this study by examining other protective factors which can be enhanced to cope with the stress that comes with the school environment.

\section{REFERENCES}

[1] Abadiano, M., Corvera, M., Yao, I., Susvilla, K., Albior, N., Salapi, F., Sombrio, T., Maceda, S., Pepito, R., Ronolo, W., Kho, M., Bargamento, R., Paninsoro, M., Malapitan, H., Solon, E., \&Salahid, V. (2015). Depression \& Suicide: Risk Factors, Warning Signs, and Prevention. International Journal of Social Science and Humanities Research. Vol. 3, Issue 1, pp: (1-10). Retrieved from www.researchpublish.com
[2] Abdel Wahed, W.Y., \& Hassan, S.K. (2015). Prevalence and Associated Factors of Stress, Anxiety and Depression amongMedical Fayoum University Students. Alexandria Journal of Medicine. Retrieved from http://www.elsevier.com/locate/ajme September 2018.

[3] About the Beck Depression Inventory. (2011, April). Retrieved from https://counsellingresource.com/quizzes/depressiontesting/beck

[4] Al Qahtani, A. \& Al Qahtani, N. (2017). Prevention of Depression: A Reviewof Literature. Journal of Depression and Anxiety, 6:4. doi: 10.4172/2167-1044.1000292.

[5] Al Raddadi, W., Aljabri, J., Kareem, M., Alattas, A., \&Alkhalawi, M. (2017). The Prevalence of Depression and Anxiety among Medical Students in Comparison with NonMedical Students: A Cross-Sectional Study in Taibah University, Al Madinah Al Munawwarah, Saudi Arabia. International Journal of Academic Scientific Research. ISSN: 2272-6446 Volume 5, Issue 1 (February - March 2017), PP 72-80. Retrieved from www.ijasrjournal.org

[6] Almojali, A.I., Almalki, S. A., Alothman, A. S., Masuadi, E. M., Alaqeel, M, K., (2017). The Prevalence and Association of Stress with Sleep Quality among Medical Students. Journal of Epidemiology and Global Health 7 (2017) 169-174. Retrieved on September 2018 from www.elsevier.com/locate/jegh.

[7] Anuradha, R., Dutta, R., Raja, J. D., Sivaprakasam, P., \& Patil, A. B. (2017).Stress and Stressors among Medical Undergraduate Students: A Cross-sectional Study in a Private Medical College in Tamil Nadu. Indian Journal of Community Medicine: Official Publication of Indian

[8] Association of Preventive \& Social Medicine,2(4), 222-225. http://doi.org/10.4103/ijcm.IJCM_287_16

[9] Banerjee, N., \& Chatterjee, I., (2016). Academic Stress, Suicidal Ideation \& Mental Well-being among 1st Semester \& 3rd Semester Medical, Engineering \& General Stream Students. Retrieved from URL: http://dx.doi.org/10.18843/rwjasc/v7i3/09

[10] Basnet, B., Jaiswal, M., Adhikari, B., \&Shyangwa, P.M. (2012). Depression Among Undergraduate Medical Students. Kathmandu Univ Med J 2012; 39(3):56-59.doi: 10.3126/kumj.v10i3.8021.

[11] Beck, A., Ward, C., Mendelson, M., Mock, J., \& Erbaugh, J. (1961). An Inventory for Measuring Depression. Archives of General Psychology, 4: 561-571.

[12] Bedewy, D. \& Gabriel, A. (2015). Examining Perceptions of Academic Stress and Its Sources among University Students: The Perception of Academic Stress Scale.doi: $10.1177 / 2055102915596714$

[13] Beiter, R., Nash, R., McCrady, M., Rhoades, D., Linscomb, M., Clarahan, M., Sammut, S., (2015). The Prevalence and Correlates of Depression, Anxiety, and Stress in a Sample of College Students. Journal of Affective Disorders 173 (2015) 90-96. Retrieved fromhttp://dx.doi.org/10.1016/j.jad.2014.10.054 on September 2018.

[14] Borjalilu, S., Mohammadi, A. \&Mojtahedzadeh, R. (2015). Sources and Severity of Perceived Stress Among Iranian Medical Students. Iran Red Crescent Med J. Department of Elearning in Medical Education, Virtual School, Tehran University of Medical Sciences, Tehran, IR Iran. October; 17(10): e17767. doi: 10.5812/ircmj.17767

[15] Bulo, J.G. \& M.G. Sanchez (2014). Sources of Stress among College Students. CVCITC Research Journal, 1 (1), pp $16-25$. Retrieved from http://www.academia.edu/7498186/

[16] Calaguas, G.M. (2012). Survey of College Academic Stressors: Development of a New Measure. International Journal of Human $\begin{array}{llll}\text { Sciences } & \text { [Online]. } & 9: 1 . & \text { Retrieved from }\end{array}$ http://www.insanbilimleri.com/en

[17] Chelala, C. (2013). Untreated Mental Health Issues a Global Reality. Retrieved from https://www.theepochtimes.com/untreated-mental-health-healthissues-a-global-reality_108595.html

[18] Civitci, A. (2015). Perceived Stress and Life Satisfaction in College Students: Belonging and Extracurricular Participation as Moderators. Retrieved from 
http://creativecommons.org/licenses/by-nc-nd/4.0/).

doi: 10.1016/j.sbspro.2015.09.077.

[19] Cuttilan, A.N., Sayampanathan, A.A., \& Chun-Man Ho, R. (2016). Mental Health Issues Amongst Medical Students in Asia: A SystematicReview [2000-2015]. Retrieved from http://dx.doi.org/10.3978/j.issn.2305-5839.2016.02.07.

[20] Depression.(2018, March 22). Retrieved from http://www.who.int/mediacentre/factsheets/fs369/en/

[21] Devynck, F., Rousseau, A. \& Romo, L. (2019). Does Repetitive Negative Thinking Influence Alcohol Use? A Systematic Review of the Literature.Front. Psychol. 10:1482. Retrieved from doi: 10.3389/fpsyg.2019.01482

[22] Du, J., Huang, J., An, Y., \& Xu, W. (2018). The Relationship between Stress and Negative Emotion: The Mediating Role of Rumination. School of Psychology, Nanjing Normal University, Nanjing, P.R. China. doi: 10.15761/CRT.1000208

[23] Elias, H., Ping, W.S., \& Abdullah, M.C., (2011). Stress and Academic Achievement among Undergraduate Students in Universiti Putra Malaysi. Procedia - Social and Behavioral Sciences 29646-655. Elsevier Ltd. Retrieved from https://doi.org/10.1016/j.sbspro.2011.11.288.

[24] Essel, G. \& Owusu, P. (2017). Causes of Students' Stress, Its Effects on Their Academic Success, and Stress Management by Students. Retrieved from https://www.theseus.fi/bitstream/handle/10024/124792/

[25] Eva, E.O., Islam, M.Z., Mosaddek, A.S., Rahman, M.F., Rozario, R.J., Hassan Iftekhar, A.F., Ahmed, T.S., Jahan, I., Abubakar, A.R., Wan Dali, W.P.E., Razzaque, M.S., Bin Habib, R. \& Haque, M. (2015). Prevalence of Stress among Medical Students: A Comparative Study Between Public and Private Medical Schools in Bangladesh. BMC Res Notes. doi 10.1186/s13104015-1295-5

[26] Garg, K., Agarwal, M., \& Dala, P.K. (2017). Stress among medical students: A cross-sectional study from a North Indian Medical University.Indian J Psychiatry, 2017 Oct-Dec; 59(4): 502-504. Retrieved from doi: 10.4103/psychiatry.IndianJPsychiatry_239_17

[27] Hayes, A. (2012). Methodology in the social sciences. Introduction to mediation, moderation, and conditional process analysis: A regression-based approach. Guilford Press.

[28] Houpy, J., Lee, W.W., Woodruff, W., \&Pincavage, A. (2017). Medical Student Resilience and Stressful Clinical Events During Clinical Training. Medical Education Online, 2017 VOL. 22, 1320187. Retrieved https://doi.org/10.1080/10872981.2017.1320187

[29] Jai Prakash, H. \&Prabhu, A. (2014). A Study of Depression among Medical Students of Private Medical College in South India. Journal of Evolution of Medical and Dental Sciences 2014; Vol. 3, Issue 15, April 14; Page: 3856-3862. doi: 10.14260/jemds/2014/2366

[30] Janus, K., Lehrer, M., Gloria, C., \& Steinhardt, M. (2017). Resilience Moderates the Effect of Stress on Depressive Symptoms in Adolescent Girls. Health Behavior and Policy Review, Volume 4, Number 3, May 2017, pp. 235244(10).Retrieved from https://doi.org/10.14485/HBPR.4.3.4

[31] Jayanthi, P., Thirunavukarasu, M. \&Rajamanickam, R. (2014). Academic Stress and Depression among Adolescents: A Cross-sectional Study. Indian Pediatrics. 2015, 52: 217. https://doi.org/10.1007/s13312-015-0609-y

[32] Kapıkıran, Ş. \&Acun-Kapıkıran, N. A. (2016). Optimism and Psychological Resilience in Relation to Repressive Symptoms in University Students: Examining the Mediating Role of Self-esteem. Educational Sciences: Theory \& Practice, 16, 2087- 2110. doi: 10.12738/estp.2016.6.0107

[33] Kiecolt-Glaser, J., McGuire, L., Robles, T., \& Glaser, R. (2002). Emotions, morbidity, and mortality: New Perspectives FromPsychoneuroimmunology. Annual review of psychology 53: 83-107.

[34] Ku, Y. (2017). A Moderated Mediation Model of Negative Life Events, Dysfunctional Attitudes, the Cognitive Triad and
Depressive Symptoms. JDepress Anxiety 6: 279. doi:10.4172/2167- 1044.1000279

[35] Kumar, S. G., Kattimani, S., Sarkar, S., \& Kar, S. S. (2017). Prevalence of Depression and Its Relation to Stress Level among Medical Students in Puducherry, India. Industrial $\begin{array}{lll}\text { Psychiatry } \quad \text { Journal, } & \text { 26(1), }\end{array}$ http://doi.org/10.4103/ipj.ipj_45_15

[36] Lee, R., Maria, M.S., Estanislao, S., \& Rodriguez, C. (2013). Factors Associated with Depressive Symptoms Among Filipino University Students. PLoS ONE 8(11): e79825. doi:10.1371/journal.pone.0079825

[37] Melaku, L., Mossie, A. \&Negash, A., (2015). Stress among Medical Students and Its Association with Substance Use and Academic Performance. Hindawi Publishing Corporation Journal of Biomedical Education, Volume 2015, Article ID 149509, 9 pages. Retrieved from http://dx.doi.org/10.1155/2015/149509

[38] Merchant, H., Mulkawar, A. \& Nayak, A. (2018) A Study To Assess The Prevalence of Depression, Anxiety and Stress Among Undergraduate Medical Students Across The Stateof Maharashtra, India. Global journal for research analysis international. Volume-7, Issue-4, April-2018 • ISSN No $2277-8160$.

[39] Miletic, M., Lukovic, J.A., Ratkovic, N., Aleksic, D., \&Grgurevic, A., (2013). Demographic Risk Factors for Suicide and Depression among Serbian Medical School Students. Social Psychiatry Epidemiology 50:633-638. doi 10.1007/s00127-0140950-9.

[40] Mohamad, M.H., Mohamad, M.S., Subhi, N., Baidi, N. \& Nor Asshidin, N.H. (2018). The Relationship Between Mental Health, Stress and Academic Performance Among College Students. Retrieved https://www.researchgate.net/publication/308170193.

[41] Onyishi, M., Talukdar, D., Sanchez, R., Olaleye, A.O., Medavarapu, S., (2016). Prevalence of Clinical Depression among Medical Students and Medical Professionals: A Systematic Review Study. Arch Med. 2016, 8: 6. Retrieved from http://www.archivesofmedicine.com/medicine, September 2018

[42] Parekh, R. (2017). What is Depression. [Review of the article What is Depression by APA]. Retrieved from https://www.psychiatry.org/patients-families/depression/what-isdepression

[43] Pinquart, M. (2008). Moderating Effects of Dispositional Resilience on Associations between Hassles and Psychological Distress. Journal of Applied Developmental Psychology 30 (2009) 53-60. doi:10.1016/j.appdev.2008.10.005

[44] Puthran, R., Zhang, M.W., Tam, W., \& Ho, R. (2016). Prevalence of Depression amongst Medical Students: A Meta-analysis. Medical Education 2016: 50: 456-468. doi: 10.1111/medu.12962.

[45] Rood, L., Roelofs, J., Bo"gels, S. \&Meesters, C. (2012). J Youth Adolescence 41:414-425. Retrieved from doi: 10.1007/s10964011-9657-3

[46] Rosiek, A., Rosiek-Kryszewska, A., Leksowski, Ł., \&Leksowski, K. (2016). Chronic Stress and Suicidal Thinking Among Medical Students. Int J Environ Res Public Health. 2016 Feb 15;13(2):212. doi: 10.3390/ijerph13020212

[47] Saeed, A.A., Bahnassy, A.A., Al-Hamdan, N.A., Almudhaibery, F.S., \&Alyahya, A.Z. (2016). Perceived Stress and Associated Factors among Medical Students. J Fam Community Med 23 :166-71. doi: 10.4103/2230-8229.189132

[48] Sagone, E., \& De Caroli, M.E., (2013). Relationships between Resilience, Self-Efficacy, and Thinking Styles in Italian Middle Adolescents. Procedia - Social and Behavioral Sciences 92 (2013) $838-845 . \quad$ Retrieved from https://core.ac.uk/download/pdf/82619739.pdf

[49] Saravanan, C. \& Wilks, R., (2014). Medical Students' Experience of and Reaction to Stress: The Role of Depression and Anxiety. HindawiPublishing Corporation .e Scientific World Journal, Volume 2014, Article ID 737382, 8 pages. Retrieved http://dx.doi.org/10.1155/2014/737382 
[50] Sarkar, S., Gupta, R., Menon, V. (2017). A Systematic Review of Depression, Anxiety, and Stress among Medical Students in India. J Mental Health Human Behavior; 22:88 - 96. doi: 10.4103/jmhhb.jmhhb_20_17

[51] Sarokhani, D., Delpisheh, A., Veisani, Y., Sarokhani, M.T., Manesh, R.E. \& Sayehmiri, K. (2013). Prevalence of Depression among University Students: A Systematic Review and Meta-Analysis Study. Hindawi Publishing Corporation Depression Research and Treatment Volume 2013, Article ID 373857, 7 pages. Retrieved from http://dx.doi.org/10.1155/2013/373857

[52] Shah, M., Hasan, S., Malik, S., \& Sreeramareddy, C.T., (2010). Perceived Stress, Sources and Severity of Stress among Medical Undergraduates in a Pakistani Medical School. BMC Medical Education 2010, 10:2. Retrieved from http://www.biomedcentral.com/1472-6920/10/2, September 2018.

[53] Skipworth, K. (2011). Relationship between Perceived Stress and Depression in College Students. Retrieved from https://repository.asu.edu/

[54] Sohail, N. (2012). Stress and Academic Performance Among Medical Students. Journal of the College of Physicians and Surgeons Pakistan 2013, Vol. 23 (1): 67-71. Retrieved from https://www.jcpsp.pk/archive/2013/Jan2013/15.pdf

[55] Solomon, O. (2013). Exploring the Relationship between Resilience, Perceived Stress and Academic Achievement. Retrieved from https://e-space.mmu.ac.uk/576570/

[56] Surzykiewicz, J., Konaszewski, K., \&Wagnild, G. (2019). Polish Version of the Resilience Scale (RS-14): A Validity and Reliability Study in Three Samples. Front.Psychology. https://doi.org/10.3389/fpsyg.2018.02762

[57] Tafet, G. \&Nemeroff, C. (2016). The Links between Stress and Depression: Psychoneuroendocrinological, Genetic and EnvironmentalInteractions. doi:10.1176/appi.neuropsych.15030053

[58] Talwar, P. (2016). The Moderating Effect of Perceived Social Support on Stress and Depression among University Students. Online J Health Allied Scs. 2016; 15(3):3. Retrieved from http://www.ojhas.org/issue59/2016-3-3.html.

[59] Wagnild, G. (2009). A Review of the Resilience Scale. Journal of Nursing Measurement. Vol. 17, No. 2. Retrieved from https://www.questia.com/library/journal/1P3-1825395771/areview-of-the-resilience-scale

[60] Wang, C. (2013). Depression and Suicide Behavior among College Students: Understanding the Moderator Effects of SelfEsteem and Suicide Resilience. Electronic Theses and Dissertations. Paper 686. Retrieved from https://digitalcommons.du.edu

[61] Yates, T. Tyrell, F. \&Masten, A. (2014). Resilience Theory and the Practice of Positive Psychology From Individuals to Societies. Retrieved from https://doi.org/10.1002/9781118996874.ch44

[62] Zimmerman, M. (2013). Resiliency Theory: A Strengths-Based Approach to Research and Practice for Adolescent Health. Health Educ Behav. 2013 August; 40(4): 381-383. doi: $10.1177 / 1090198113493782$ 